\title{
Web-based interventions for prevention and treatment of perinatal mood disorders: a systematic review
}

\author{
Eleanor W. Lee ${ }^{1}$, Fiona C. Denison' ${ }^{1}$, Kahyee $\mathrm{Hor}^{2}$ and Rebecca M. Reynolds ${ }^{1,3^{*}}$
}

\begin{abstract}
Background: Perinatal depression is strikingly common with a prevalence of 10-15\%. The adverse effects of perinatal depression on maternal and child health are profound with considerable costs. Despite this, few women seek medical attention. E-health, providing healthcare via the Internet is an accessible and effective solution for the treatment of depression in the general population. We aimed to conduct a systematic review of web-based interventions for the prevention and treatment of mood disorders in the perinatal period, defined as the start of pregnancy to 1 year post-partum.

Methods: Six databases were searched until $26^{\text {th }}$ March 2015. Two researchers independently screened articles for eligibility. Of the 547 screened articles, four met the inclusion criteria. These included three randomised-controlled trials and one feasibility trial, with total data from 1274 participants. MOOSE and PRISMA guidelines were adhered to for the conduct and reporting of the systematic review.

Results: All studies were conducted in the post-partum period. All reported an improvement in maternal mood following intervention. A significant improvement in depressive symptoms was measured using validated rating scales, such as the Edinburgh Postnatal Depression Scale (EPDS), either at post-treatment or follow-up which ranged from 3 to 12 months post study completion. For the two RCTs utilising the EPDS, the EPDS score reductions were (mean \pm SEM) $8.52 \pm 0.22$ (Range 19.46 to 10.94) and $9.19 \pm 0.63$ (Range, 20.24 to 11.05) for treatment groups and $5.16 \pm 0.25$ (Range 19.44 to 14.28) and $6.81 \pm 0.71$ (Range 21.07 to 14.26) for comparator groups. However attrition within studies ranged from 13 to $61 \%$. One study was rated as 'good' quality.

Conclusions: Preliminary data suggests web-based therapies for perinatal depression delivered in the post-partum period may play a role in improving maternalmood but more studies are needed, particularly with interventions delivered antenatally. Further research is needed to address the limitations of the existing evidence base.
\end{abstract}

Keywords: CBT, Web-based, Perinatal, Depression, Pregnancy

\section{Background}

Depression during the perinatal period is common, occurring in $10-15 \%$ of pregnancies $[1,2]$, with the prevalence of depression peaking at 3 months postpartum. The adverse effects of perinatal depression on maternal

\footnotetext{
* Correspondence: R.Reynolds@ed.ac.uk

'Tommy's Centre for Maternal and Fetal Health, University of Edinburgh, Queen's Medical Research Institute, 47 Little France Crescent, Edinburgh EH16 4TJ, Scotland

${ }^{3}$ Endocrinology Unit, University/British Heart Foundation Centre for Cardiovascular Science, University of Edinburgh, Queen's Medical Research Institute, 47 Little France Crescent, Edinburgh EH16 4TJ, Scotland Full list of author information is available at the end of the article
}

and child health are profound [3-6] with estimated costs to the UK of $£ 8.1$ billion per year [7]. The Saving Mothers' Lives Report (2011) identified 29 women who died as a result of suicide between 2006 and 2008 [8]. Of these 29 women, 6 of them $(21 \%)$ had an underlying diagnosis of severe depressive illness. Despite this, few women seek professional advice due to physical and attitudinal barriers, long-waiting times for face-to-face psychotherapies, social stigma [9-13] and uncertainties about the potential risks of pharmacological therapies during pregnancy [14-16]. There is therefore an urgent need for a validated, effective, easily accessible, low-cost, 
non-pharmacological psychosocial evidence-based intervention to prevent or treat perinatal depression.

Computerised Cognitive Behavioural Therapy (CCBT) has proved an acceptable and effective treatment for depression in non-pregnant individuals [17-26] with a comprehensive meta-analysis demonstrating significant superiority compared to comparator therapies in the general population [18]. Based on this evidence, CCBT is one of the low-intensity psychosocial interventions that the National Institute for Health and Care Excellence (NICE) (which provides national guidelines for delivery of healthcare in England and Wales in the UK) recommends for treating persistent subthreshold depressive symptoms or mild to moderate depression in nonpregnant individuals [27].

NICE also suggests that CCBT should be offered to treat perinatal depression [28]. This is despite the scarcity of psychosocial interventions specifically designed to treat perinatal depression (particularly that originating antenatally) and the changing and specific psychosocial needs of women during pregnancy and post-partum [29, 30]. Further, women are increasingly using the Internet as a source of health information during pregnancy. For example, in a study of 613 women, almost $50 \%$ used the Internet to enhance their involvement in pregnancy-related decisionmaking [31] and $90 \%$ felt that health professionals should actively suggest suitable Internet sites to guide their further reading during pregnancy [31]. A CCBT resource for the self-management of perinatal depression could therefore represent an efficacious, accessible and economically sound resource [32]. CCBT also provides a level of anonymity not possible in clinical care, can be accessed at a time and place suitable for the participant and can be adapted to different cultures, languages and literacy levels to ensure the inclusion of vulnerable groups [33]. However, before CCBT is embedded in clinical practice for treatment of perinatal depression, there is a need for a systematic review of the existing evidence to determine whether web-interventions for pregnant and post-partum women are efficacious for prevention and treatment of perinatal mood disorders and potentially to inform the design of future studies if gaps in the current evidence base are identified.

\section{Methods}

\section{Data sources}

The Meta-analysis of Observational Studies in Epidemiology (MOOSE) guidelines were followed for the conduct [34], and the Preferred Reporting Items for Systematic Reviews and Meta-analyses (PRISMA) guidelines for the reporting [35] of this systematic review. The literature search was conducted using MEDLINE, PsycINFO, Embase and Cumulative Index to Nursing and Allied Health Literature (CINAHL) from inception until March $26^{\text {th }} 2015$. The searches were limited to human studies and used terms as both keywords and indexing terms (Medical Subject Headings, MeSH) to identify studies related to depression AND pregnancy AND therapy AND online: 'depression,' 'depressive,' 'depressed,' 'mental-health, 'well-being,' 'post-natal depression', 'pregnancy', 'perinatal care', 'pre-natal/ante-natal care,' post-partum/post-natal care,' 'pregnancy complication, 'self-help,' 'cognitive behavioural therapy', 'behavioural therapy', 'psychotherapy', 'internet,' 'online, 'online therapy,' 'computer program,' 'mobile application', 'E-health' and 'telemedicine' (see Additional file 1 for full search strategy). Finally forward and backward citation tracking was conducted through Web of Science for all articles identified for full article review and one heavily cited review in this area [26]. One identified record was a 'letter to the editor' [36]. The corresponding author was contacted and confirmed that the data within the letter were also included in a further publication identified in the literature search [37]. In addition, the corresponding author of three articles written by the same author [38-40] was contacted who confirmed that all three publications included data collected from one single study. The data from only the largest study [40] were included in the final data synthesis to avoid data duplication. No supplementary data or further studies were identified by author contact.

\section{Study selection}

Two researchers (EL, KH) screened articles for eligibility. Any discrepancies that could not be resolved were discussed with the other researchers (FD, RR). Studies were included if they a) administered an internet/web/online/ computer intervention during the perinatal period, defined as the start of pregnancy to 1 year post-partum, b) had maternal mental health as an outcome measure and c) an assessment of mental health pre-and post-intervention. There were no exclusions related to study design or participants' age, ethnicity, socioeconomic status, parity, depressive status or depression therapy.

\section{Data extraction}

Relevant information on study characteristics and methodology (Table 1) and study results (Table 2) was extracted using pre-specified and standardised data extraction forms based on the template devised by the Cochrane Consumers and Communication Review Group [41]. One researcher (EL) completed the data extraction tables and a second researcher $(\mathrm{KH})$ independently checked content. Any disagreements were discussed and resolved by consensus.

\section{Quality assessment}

Two researchers (EL, KH) independently assessed the risk of bias for each study as an assessment of study quality, using a modified tool [42] with objective criteria relating to sample population and recruitment, intervention, randomisation, blinding, comparator group, use of 
Table 1 Data extraction: Study design and details of intervention

\begin{tabular}{|c|c|c|c|c|c|c|c|c|c|c|}
\hline First author & Year & Country & Study design & $\begin{array}{l}\text { Participant } \\
\text { number }\end{array}$ & Study population & $\begin{array}{l}\text { Depressive status } \\
\text { and treatment }\end{array}$ & Intervention & Comparator group & $\begin{array}{l}\text { Intervention } \\
\text { duration }\end{array}$ & $\begin{array}{l}\text { Timing of } \\
\text { intervention }\end{array}$ \\
\hline Danaher [45] & 2013 & $\begin{array}{l}\text { U.S. and } \\
\text { Australia }\end{array}$ & $\begin{array}{l}\text { FT with Quasi- } \\
\text { experimental } \\
\text { design }\end{array}$ & $\begin{array}{l}n=53 \text { (all } \\
\text { received } \\
\text { intervention) }\end{array}$ & $\begin{array}{l}\text { Mean age of } 31.9 \text { years (SD 5.1), } \\
\text { mean parity of } 2 \text { (SD 1.1), mean } \\
\text { baby age of } 5.5 \text { months at } \\
\text { pre-test (SD } 2.9), 26 \% \text { graduate } \\
\text { or higher level degrees. }\end{array}$ & $\begin{array}{l}\text { All participants had EPDS of } \\
12-20 \text { or PHQ-9 of 10-19. } \\
49 \%(26 / 53) \text { met DSM-IV } \\
\text { criteria for MDD (SCID). No } \\
\text { participants were undergoing } \\
\text { current treatment for } \\
\text { depression. }\end{array}$ & $\begin{array}{l}6 \text { weekly online sessions, } \\
\text { weekly phone calls from } \\
\text { a personal coach plus } \\
\text { automatic email reminders, } \\
\text { private peer-based web } \\
\text { forum, separate partner site }\end{array}$ & None & 6-12 weeks & Post-natal \\
\hline Kersting [40] & 2013 & Germany & RCT & $\begin{array}{l}n=228(\text { TG } \\
115, \text { WLC 113) }\end{array}$ & $\begin{array}{l}228 \text { participants, } 92 \% \text { female, } \\
\text { mean age of } 34.18 \text { years, mean } \\
\text { of } 9.93 \text { months since losing a } \\
\text { pregnancy at a mean gestation } \\
\text { of } 17.8 \text { weeks. }\end{array}$ & $\begin{array}{l}\text { Applicants with severely } \\
\text { depressed mood/suicidal } \\
\text { ideation (DSM-IV criteria) } \\
\text { were excluded. No participants } \\
\text { were currently receiving } \\
\text { additional treatment. }\end{array}$ & $\begin{array}{l}\text { 10x } 45 \text {-minute writing } \\
\text { exercises assigned } \\
\text { biweekly based on CBT. } \\
3 \text { treatment phases: } \\
\text { self-confrontation, } \\
\text { cognitive reappraisal, } \\
\text { social sharing. Therapist } \\
\text { contact with feedback } \\
\text { and instruction twice } \\
\text { per phase }\end{array}$ & WLC & 5 weeks & $\begin{array}{l}\text { Following } \\
\text { loss of } \\
\text { pregnancy }\end{array}$ \\
\hline O'Mahen [43] & 2013 & UK & RCT & $\begin{array}{l}n=910 \text { (TG } \\
462, \text { TAU 448) }\end{array}$ & $\begin{array}{l}910 \text { women, mean age of } \\
32.3 / 32.2(\mathrm{TG} / \mathrm{TAU}) \text {, with a } \\
\text { child }<12 \text { months old. } \\
\text { Varied socioeconomic status. }\end{array}$ & $\begin{array}{l}\text { Inclusion criteria of EPDS }>12 \text {. } \\
\text { Participants were permitted } \\
\text { to be currently receiving } \\
\text { treatment (medical } \\
\text { or psychological). }\end{array}$ & $\begin{array}{l}11 \times 40-\text { minute online } \\
\text { sessions completed } \\
\text { weekly. Based on } \\
\text { behavioural activation } \\
\text { principles. Weekly email } \\
\text { reminders with links to } \\
\text { homework exercises. } \\
\text { Optional weekly online } \\
\text { 'clinics' with 'real-time' } \\
\text { responses to questioning. } \\
\text { Intervention-specific } \\
\text { chat room. }\end{array}$ & $\begin{array}{l}\text { TAU with access to } \\
\text { Netmums general } \\
\text { depression chat- } \\
\text { room }\end{array}$ & 15 weeks & Post-natal \\
\hline O'Mahen [44] & 2014 & UK & RCT & $\begin{array}{l}n=83 \text { (TG 41, } \\
\text { TAU 42) }\end{array}$ & $\begin{array}{l}83 \text { women, > } 18 \text { years, } \\
\text { vast majority Caucasian } \\
\text { (Intervention }=92.6 \% \\
\text { and TAU }=92.9 \% \text { Caucasian) }\end{array}$ & $\begin{array}{l}\text { All women met DSM-IV } \\
\text { criteria for MDD and had } \\
\text { an EPDS of }>12 \text {. }\end{array}$ & $\begin{array}{l}12 \text { online sessions with } \\
\text { weekly telephone support } \\
\text { sessions ( } 20-30 \text { mins) } \\
\text { based on behavioural } \\
\text { activation. The sessions } \\
\text { involved interactive } \\
\text { exercises and worked } \\
\text { examples. Supplemented } \\
\text { by other Netmums } \\
\text { features; 'meet a mum' } \\
\text { and moderated chat room. }\end{array}$ & $\begin{array}{l}\text { TAU with access to } \\
\text { Netmums general } \\
\text { depression chat- } \\
\text { room }\end{array}$ & 12 weeks & Post-natal \\
\hline
\end{tabular}


Table 2 Data extraction: Outcomes

\begin{tabular}{|c|c|c|c|c|c|c|c|}
\hline First author & $\begin{array}{l}\text { Primary } \\
\text { Outcome } \\
\text { Measure }\end{array}$ & $\begin{array}{l}\text { Other Outcome } \\
\text { Measure(s) }\end{array}$ & $\begin{array}{l}\text { Assessment } \\
\text { measure(s) } \\
\text { for } \\
\text { depression/ } \\
\text { anxiety }\end{array}$ & $\begin{array}{l}\text { Assessment } \\
\text { time-points }\end{array}$ & Attrition and Adherence & Results & Limitations \\
\hline $\begin{array}{l}\text { Danaher } \\
\text { [45] }\end{array}$ & $\begin{array}{l}\text { Depressive } \\
\text { symptoms, } \\
\text { acceptability } \\
\text { and } \\
\text { feasibility }\end{array}$ & $\begin{array}{l}\text { Automatic } \\
\text { thoughts, dyadic } \\
\text { adjustment, } \\
\text { parenting sense } \\
\text { of competence, } \\
\text { self-efficacy }\end{array}$ & $\begin{array}{l}\text { EPDS (only } \\
\text { for pre-test } \\
\text { screening) } \\
\text { and HRSD, } \\
\text { PHQ-9 }\end{array}$ & $\begin{array}{l}\text { Pre-test, Post-test } \\
(3 \text { months) and } \\
\text { follow-up ( } 6 \text { months), } \\
\text { PHQ-9 during coach } \\
\text { calls at } 2 \text { and } 4 \text { weeks } \\
\text { additionally }\end{array}$ & $\begin{array}{l}\text { All } 6 \text { sessions of the program were } \\
\text { completed by } 87 \% \text { ( } 46 / 53 \text { ) of participants. } \\
\text { Posttest data were collected from } 89 \% \text { of } \\
\text { participants }(47 / 53) \text { with the exception of } \\
\text { the HRSD }(45 / 53,85 \% \text { ) and } 6 \text {-month } \\
\text { follow-up data were collected from } 87 \% \\
\text { of participants ( } 46 / 53) \text {. Overall attrition was } \\
13 \% \text { ( } 7 / 53 \text { ) from pretest to } 6 \text {-month } \\
\text { follow-up. Average of } 5.6 / 6 \text { sessions } \\
\text { viewed. }\end{array}$ & $\begin{array}{l}\text { PHQ-9 scores decreased from pretest } \\
\text { (mean 12.6, SD 4.1) to posttest (mean 5.0, } \\
\text { SD 4.4) and the 6-month follow-up (mean } \\
\text { 4.2, SD 3.9) ( } p<0.001 \text { ) with large effects } \\
\text { post-test (partial } r=0.77 \text { ) and 6-month } \\
\text { follow-up (partial } r=0.82 \text { ). At pretest, } 55 \% \\
\text { (29/53) participants met PHQ-9 criteria for } \\
\text { minor or major depression. At posttest, } \\
90 \% \text { (26/29) no longer met these PHQ-9 } \\
\text { criteria. HRSD scores also decreased from } \\
\text { pretest (mean 16.9, SD 6.9) to posttest } \\
\text { (mean 7.0, SD 5.6) and the 6-month } \\
\text { follow-up (mean 6.6, SD 6.8). Changes } \\
\text { from pretest were statistically significant } \\
\text { (P<.001) with large effects at posttest } \\
\text { (partial } r=.75 \text { ) and 6-month follow-up } \\
\text { (partial } r=.71 \text { ). }\end{array}$ & $\begin{array}{l}\text { No comparator group, women were } \\
\text { allowed to engage with other therapies } \\
\text { (e.g., pharmacotherapy, counselling) } \\
\text { during the trial and thus it is difficult to } \\
\text { deduce individual effect of intervention, } \\
\text { 'coach' reliant. Quasi-experimental design } \\
\text { with small convenience sampleQuality } \\
\text { score: poor }\end{array}$ \\
\hline Kersting[40] & $\begin{array}{l}\text { Prolonged } \\
\text { grief, PTSD }\end{array}$ & $\begin{array}{l}\text { General } \\
\text { psychopathology } \\
\text { (including } \\
\text { depression and } \\
\text { anxiety) }\end{array}$ & $|C G, B S|$ & $\begin{array}{l}\text { Baseline, post- } \\
\text { treatment and 3- } \\
\text { month and } 12- \\
\text { month follow up }\end{array}$ & $\begin{array}{l}86.1 \% \text { in the TG completed the } \\
\text { intervention. WLC had a completion } \\
\text { rate of } 88.5 \% \text {. Dropouts were younger. }\end{array}$ & $\begin{array}{l}\% \text { of participants scoring }>\text { ICG-R cut-off } \\
\text { for prolonged grief differed significantly } \\
\text { at post-treatment }(\mathrm{TG}=28.7 \% \text {, WLC }= \\
47.8 \% \text { ) Mean depression scores for TG } \\
\text { were significantly decreased at post- } \\
\text { treatment }(1.19 \rightarrow 0.61, \mathrm{t}(114)=7.98, p \\
<0.001) \text { Same for anxiety }(0.7 \rightarrow 0.37) \text {. } \\
\text { Depression scores continued to im- } \\
\text { prove in follow-up measurements. }\end{array}$ & $\begin{array}{l}\text { Heavily therapist reliant, well- } \\
\text { educated sample, questionable rele- } \\
\text { vance to perinatal depression, inten- } \\
\text { sive - high level of participant } \\
\text { engagement required. Male partici- } \\
\text { pants were included. Self-rating ques- } \\
\text { tionnaire to rate } \\
\text { psychotherapyQuality score: } \\
\text { intermediate }\end{array}$ \\
\hline O'Mahen[43] & $\begin{array}{l}\text { Feasibility, } \\
\text { acceptability, } \\
\text { depressive } \\
\text { symptoms }\end{array}$ & None & EPDS & $\begin{array}{l}\text { At sign-up to the } \\
\text { trial and } 15 \text {-weeks }\end{array}$ & $\begin{array}{l}18.9 \% \text { (172/910) completed the longer } \\
\text { baseline questionnaires. The } 15-\text {-week } \\
\text { follow-up EPDS was completed by } 39 \% \\
\text { (181/462) in treatment group and } 36 \% \\
\text { in TAU (162/448). Fewer participants } \\
\text { completed the acceptability } \\
\text { questionnaires. }\end{array}$ & $\begin{array}{l}\text { Improvement in depressive symptoms } \\
\text { for } 61.3 \%(n=111 / 181) \text { of TG and } \\
41.4 \%(n=67 / 162) \text { for TAU group. } \\
\text { When all non-respondents are counted } \\
\text { as depressed the intervention is still } \\
\text { favoured. } 115 / 462 \text { (intervention) vs } 71 / \\
448 \text { (TAU) were not depressed. }\end{array}$ & $\begin{array}{l}\text { Extremely high attrition rates - follow-up } \\
\text { EPDS was completed by less than } 40 \% \\
\text { in each group, only } 1 \text { measure of depres- } \\
\text { sive symptoms, Imperfect intervention - } \\
\text { women reported struggle 'keeping up.' } \\
\text { Online Recruitment.Quality score: } \\
\text { intermediate }\end{array}$ \\
\hline O'Mahen[44] & $\begin{array}{l}\text { Depression } \\
\text { and anxiety, } \\
\text { attrition and } \\
\text { adherence }\end{array}$ & $\begin{array}{l}\text { Work and social } \\
\text { impairment, social } \\
\text { support, postnatal } \\
\text { bonding, health } \\
\text { service utilization. }\end{array}$ & EPDS, GAD-7 & $\begin{array}{l}\text { Baseline, } 17 \text { weeks } \\
\text { and } 6 \text { months post- } \\
\text { treatment }\end{array}$ & $\begin{array}{l}86 \%(71 / 83) \text { completed EPDS at post- } \\
\text { treatment and } 71 \%(59 / 83) \text { at } 3 \text { month } \\
\text { follow-up. Women completed an aver- } \\
\text { age of } 8 \text { (SD } 4.5) \text { telephone support ses- } \\
\text { sions and } 5.36(\mathrm{SD}=4.62) \text { online } \\
\text { modules }\end{array}$ & $\begin{array}{l}\text { Clinically significant improvement in } \\
\text { depression scores in } 62.2 \%(n=23 / 37) \\
\text { of TG compared to } 29.4 \%(n=10 / 34) \text { of } \\
\text { TAU.Odds ratio }=0.26(95 \% \mathrm{Cl} 0.10-0.71) \\
\text { after adjustment for baseline EPDS } \\
\text { scores. Large Cohen's } \mathrm{d}^{\mathrm{b}} \text { effect sizes for } \\
\text { EPDS }(-0.87,95 \% \mathrm{Cl}-0.42 \text { to }-1.32) \text { and } \\
\text { GAD-7 }(-0.59,95 \% \mathrm{Cl}-1.11 \text { to }-0.07) \text {. }\end{array}$ & $\begin{array}{l}\text { Online sample recruitment might give a } \\
\text { sample that is more accepting and } \\
\text { responsive to internet-based therapy, } \\
\text { unable to assess the impact of telephone } \\
\text { support vs. web-modules, only } 1 \text { follow- } \\
\text { up assessment point, not ethnically diverse } \\
\text { sample.Quality score: good }\end{array}$ \\
\hline
\end{tabular}

EDS Edinburgh Postnatal Depression Scale, HRSD Hamilton Rating Scale for Depression, PHQ-9 Patient Health Questionnaire-9, SD Standard Deviation, PTSD Post-Traumatic Stress Disorder, ICG Inventory of Complicated Grief, BSI Brief Symptom Inventory (provides several indices including the global severity index of overall mental health and indices for the subscale of depression and anxiety), TG Treatment Group, WLC Waiting List Condition, TAU Treatment As Usual, GAD-7 Generalised Anxiety Disorder Assessment - 7

${ }^{a}$ The following is a discussion excerpt from this paper although no explicit data can be found within results. "Program use duration was not significantly associated with improvement in depression as measured by trajectories of the PHQ-9" 
validated outcome measure, follow-up and data analysis. A paper could attain a maximum score of 8 , a score of 1-3 indicating poor quality, 4-6 intermediate quality and 7-8 good quality.

\section{Data analysis and synthesis}

Due to considerable study heterogeneity a descriptive synthesis of results was conducted. This included a description of the study design and sample studied, details of the intervention including mode and duration of delivery, and the outcomes including change in mood scores post intervention and at later follow-up as well as attrition rates.

\section{Results}

\section{Study design and participants}

From 547 abstracts, 39 full text articles were assessed (Fig. 1) and four studies were included in the final data synthesis. The four eligible studies included three randomised controlled trials (RCTs) [40, 43, 44] and one feasibility trial [45] (Tables 1 and 2) with data on 1274 participants from four countries. All studies included women $\geq 18$ years of age with no history or current symptoms of severe or life-threatening mental illness, proficiency in the written language of the intervention and no participation in psychotherapy at recruitment. Those study participants who met criteria for depression ranged from 'clinical impairment' to 'major depressive episode.'

\section{Intervention}

The web-based intervention was administered postnatally in all four studies [40, 43-45], one of which recruited women with a recent loss of pregnancy [40]. None of the studies administered the intervention antenatally. Intervention duration ranged from 5 to 15 weeks with all four studies employing a modular structure. In addition to a web-based component, all studies included a therapist/external contact element to the intervention. In two studies [40, 43], contact with a therapist or other professional occurred through text-based contact i.e., email, instant messenger or chat-rooms whilst two studies included telephone sessions $[44,45]$. Three studies provided their participants with access to a web-forum of the study cohort [43-45]. Studies differed in their

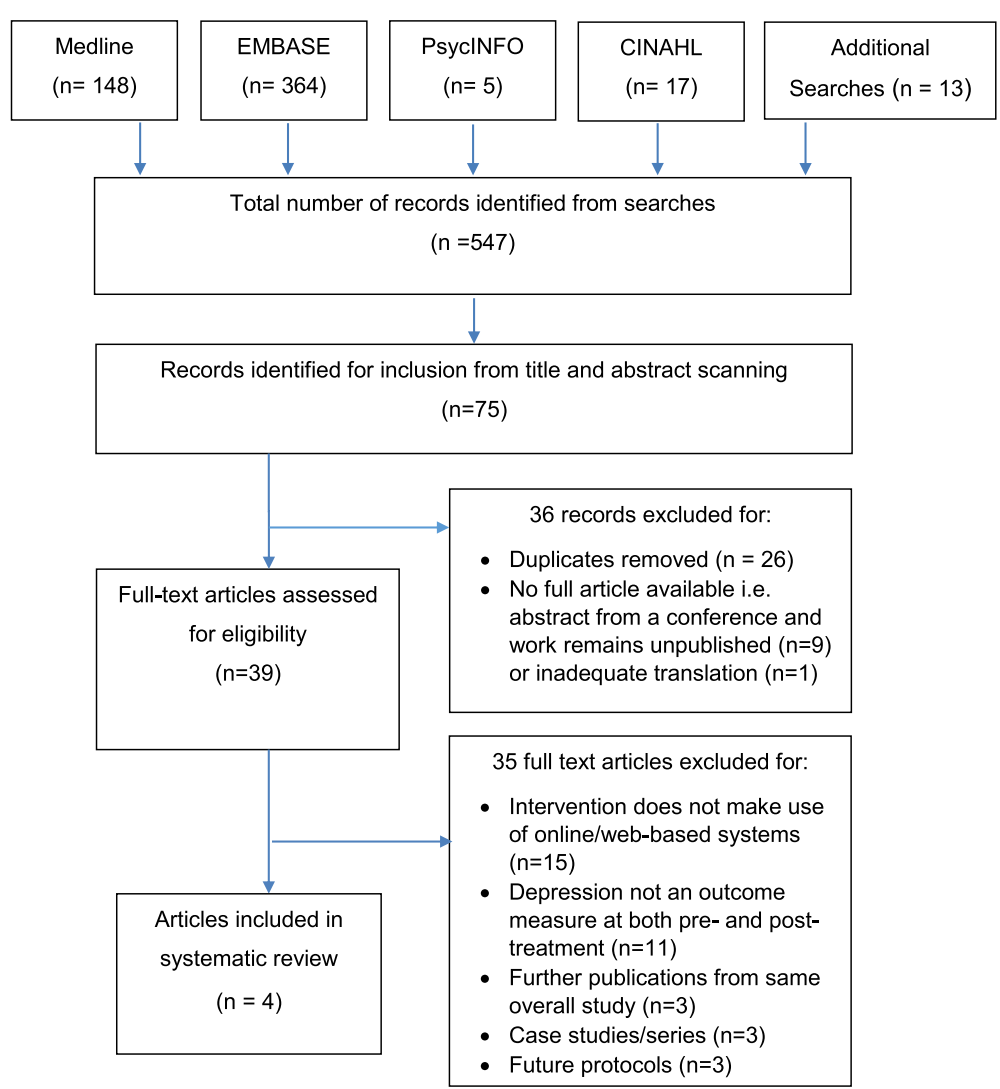

Fig. 1 Flow (PRISMA) Diagram of Included Studies. Initial searches of bibliographic databases and reference tracking identified 547 records. Applying inclusion/exclusion criteria to the title and abstract identified 75 entries for full-article analysis. This was reduced to 39 following removal of duplicates and of records that did not have a corresponding full article. 4 studies were fully eligible for inclusion in the systematic review. Reasons for exclusion are outlined within the figure 
reliance on an external support, with weekly feedback and monitoring proving a key element for some. In the three RCTs the comparator group were either assigned to treatment as usual or a waiting list condition.

\section{Outcomes}

Depressive symptoms immediately post-intervention were a primary outcome for three of the studies [43-45] and a secondary outcome for the other [40]. Other primary outcomes included complicated grief and stress. All studies used well-recognised and validated scales for assessing depressive symptoms with two studies using the Edinburgh Postnatal Depression Scale (EPDS) [43, 44]. Three of the studies used a combination of outcome measures with one reporting findings from a single measure [43]. The EPDS score reductions in the two RCTs were (mean \pm SEM) $8.52 \pm 0.22$ (Range 19.46 to 10.94) and $9.19 \pm 0.63$ (Range 20.24 to 11.05) for treatment groups and 5.16 \pm 0.25 (Range 19.44 to 14.28) and $6.81 \pm 0.71$ (Range 21.07 to 14.26) for comparator groups. Three of the studies included further follow-up at a period ranging from 3 to 12 months post-completion of the intervention. The most common follow-up points were at 3 and 6 months posttreatment. Overall, all four studies described a benefit in maternal mood following intervention, either at posttreatment or follow-up.

Overall rates of attrition in the trials ranged from 13 to $61 \%$ at the completion of the intervention assessment. However, the feasibility study [45] had extremely high attrition rates, with many women struggling to complete the intervention; excluding this study the early attrition ranged from 11 to $13 \%$. A common theme was the gradual increase in attrition as the study progressed, ranging at follow-up from 24 to $29 \%$. In one attrition was higher in younger women [40].

\section{Quality assessment}

Quality assessment revealed one study to be of good quality, scoring 7 out of 8 . Two studies were of intermediate quality (scoring 6 out of 8) where limitations included studying a selected sample (e.g., previous pregnancy loss [40], having child $<12$ months old [43] thus limiting the generalisability of findings to the general antenatal population. One study was categorised as poor. (Quality Assessment shown in Additional file 2).

\section{Discussion}

Although CCBT has been endorsed by NICE for management of depressive symptoms in the general population, this systematic review demonstrates that there has been much less work in this field in relation to the perinatal period. We identified only four studies meeting the inclusion criteria for the review, three of which were RCTs. Importantly none reported an intervention delivered in the antenatal period, highlighting an important research gap. Though there were small numbers of studies with heterogeneity of study design, participant characteristics, duration, timing and nature of the intervention, and intermediate quality of studies, the overall findings suggest web-based interventions implemented in the post-partum period improve maternal mood outcomes.

In accord with other CCBT interventions, the majority of the interventions followed a modular structure. Most also included interaction with a therapist or other health professional as part of the intervention. This complicates the interpretation of the impact of the web-based component alone. Further, web-based interventions placing great importance on therapist input do not address the financial burden of treating perinatal depression nor the waiting list delay. In the case where web-based materials are used solely to supplement therapist mediated interventions, the many practical barriers to face-to-face contact may remain.

All studies utilised a well-validated outcome measure to assess depression symptoms. There was reduction in symptom scores in all studies, with the reported reduction in the two RCTs using the EPDS as an outcome measure, considered a clinically significant improvement $[46,47]$. This review was not able to determine whether the severity of symptoms impacts on the effectiveness of CCBT. Three of the studies included longer-term follow-up assessments with the maximum follow-up at 12 months. Due to the relapsing and remitting course of depression, longer-term outcomes are important to evaluate in future studies.

Attrition rates are often high and problematic in other studies of online therapies [48, 49]. Of note the one feasibility study also had high attrition rates (less than $40 \%$ of women completing the follow-up EPDS questionnaire). However, early attrition rates in the RCTs was much lower, and comparable between studies, though notably did increase with longer-term follow-up. There was insufficient data to determine whether attrition rates were related to length or mode of intervention, or whether this differed according to the level of support given during the intervention. Further work is needed to understand the reason for this in order to gain a comprehensive understanding of the true acceptability of CCBT [50]. It is also unknown whether use of a general intervention, rather than an intervention tailored to specific concerns associated with the post-partum period or event triggering the onset of depressive symptoms impacted attrition rates. Future studies should consider use of tailored interventions specific to pregnancy, the post-partum period and pregnancy specific triggering events (e.g., antenatal stillbirth). To understand and limit attrition, future studies should also consider detailed qualitative 
assessment of reasons for completing the intervention or not, as well as acceptability of the intervention [51], and consideration of co-morbid anxiety as well as depression symptoms.

The strengths of this review include the systematic and comprehensive review process which was followed in line with PRISMA guidelines. Two researchers independently assessed eligibility of the titles, abstracts and full-text studies, extracted the data and assessed the articles for bias. There are also a number of potential limitations. The overall number of studies identified was small and none were in the antenatal period. Whilst this highlights the need for more research in this field, it does limit the interpretation of the findings. Indeed the heterogeneity of study design and lack of consistency in outcome measures meant we were unable to quantitate outcomes. Two of the studies included selected women, and one study recruited both women and their partners, limiting generalisability of the findings. Some of the studies included women with pre-existing depression or taking antidepressant therapy which may have confounded the results with treatment effects. Finally lack of information about acceptability of the interventions was a limitation of these studies.

This review highlights a number of directions for future research. More work is both warranted and necessary within the neglected area of E-health for antenatal depression. Antenatal depression has received less attention than postpartum depression, despite a similar prevalence. This is important, as antenatal depression is a major risk factor for depression in the postpartum period. Thus an intervention administered during pregnancy may also prevent the development and/or progression of antenatal depression to postpartum depression following childbirth. Whilst there is preliminary evidence that CCBT interventions are acceptable during pregnancy [51], further studies are needed to investigate the impact of such an intervention during pregnancy $[33,52,53]$. Our review would also suggest there is a need for more rigor in this field, particularly harmonisation of symptom scores used to allow future meta-analyses of outcomes. Whilst our review focused on a maternal intervention, consideration of an intervention including the partner and/or family may be an important approach for future work, particularly when the triggering event (e.g., fetal death, significant life event) is likely to affect both the woman and her partner.

\section{Conclusions}

In summary, this systematic review suggests web-based interventions may be effective for the management of maternal health in the post-partum period and highlights the need for robust, high quality studies conducted during the antenatal period.

\section{Additional files}

Additional file 1: Systematic Search Strategies. Full search strategies of all databases used within the systematic review. (PDF $107 \mathrm{~kb}$ )

Additional file 2: Quality Assessment. Quality assessment by each researcher $(\mathrm{EL} / \mathrm{KH})$ of non-case-based studies. (PDF $52 \mathrm{~kb}$ )

\section{Competing interests}

The authors declare that they have no competing interests.

\section{Authors' contribution}

EL and $\mathrm{KH}$ conducted the literature search and extracted the data. EL drafted the manuscript. RR designed the study, interpreted the data and wrote the manuscript. FD designed the study, interpreted the data and commented on the manuscript. All authors approved the final manuscript.

\section{Acknowledgments}

This study received no external funding. We acknowledge the support of Tommys and the British Heart Foundation

\section{Author details}

${ }^{1}$ Tommy's Centre for Maternal and Fetal Health, University of Edinburgh, Queen's Medical Research Institute, 47 Little France Crescent, Edinburgh EH16 4TJ, Scotland. ${ }^{2}$ Obstetrics and Gynaecology, Queen Elizabeth University Hospital, 1345 Govan Road, Glasgow G51 4TF, Scotland. ${ }^{3}$ Endocrinology Unit, University/British Heart Foundation Centre for Cardiovascular Science, University of Edinburgh, Queen's Medical Research Institute, 47 Little France Crescent, Edinburgh EH16 4TJ, Scotland.

Received: 22 August 2015 Accepted: 22 February 2016

Published online: 29 February 2016

\section{References}

1. Gavin N, Gaynes B, Lohr K. Perinatal depression: a systematic review of prevalence and incidence. Obstet Gynaecol. 2005;106(5):1071-83.

2. Melville JL, Gavin A, Guo Y, Fan M-Y, Katon WJ. Depressive disorders during pregnancy: prevalence and risk factors in a large urban sample. Obstet Gynecol. 2010;116(5):1064-70.

3. Field T. Prenatal depression effects on early development: a review. Infant Behav Dev. 2011;34(1):1-14.

4. Goodman SH, Rouse MH, Connell AM, Broth MR, Hall CM, Heyward D. Maternal depression and child psychopathology: a meta-analytic review. Clin Child Fam Psychol Rev. 2011;14(1):1-27.

5. Loomans EM, van Dijk AE, Vrijkotte TGM, van Eijsden M, Stronks K, Gemke RJBJ, et al. Psychosocial stress during pregnancy is related to adverse birth outcomes: results from a large multi-ethnic community-based birth cohort. Eur J Public Health. 2013;23(3):485-91.

6. Mina TH, Reynolds RM. Mechanisms linking in utero stress to altered offspring behaviour. In: Pariante CM, Lapiz-Bluhm MD, editors. Behavioural Neurobiology of Stress-related Disorders. Berlin, Heidelberg: Springer Berlin Heidelberg; 2014. p. 93-122.

7. Bauer A, Parsonage M, Knapp M, Lemmi V, Adelaja B. The costs of perinatal mental health problems. London School of Economics and Political Science. 2014. http://www.centreformentalhealth.org.uk/pdfs/Costs_of_perinatal_mh. pdf. Accessed 3 March 2015.

8. Deaths from Psychiatric Causes. M Oates, R Cantwell. Centre for Maternal and Child Enquiries (CMACE). In Saving Mothers' Lives: reviewing maternal deaths to make motherhood safer: 2006-08. The Eighth Report on Confidential Enquiries into Maternal Deaths in the United Kingdom. BJOG 2011;118(Suppl. 1):1-203.

9. Abrams LS, Dornig K, Curran L. Barriers to service use for postpartum depression symptoms among Low-income ethnic minority mothers in the united states. Qual Health Res. 2009;19(4):535-51.

10. Dennis C-L, Chung-Lee L. Postpartum depression help-seeking barriers and maternal treatment preferences: a qualitative systematic review. Birth. 2006; 33(4):323-31.

11. Kim JJ, La Porte LM, Corcoran M, Magasi S, Batza J, Silver RK. Barriers to mental health treatment among obstetric patients at risk for depression. Am J Obstet Gynecol. 2010;202(3):312. e1-312.e5. 
12. O'Mahen HA, Flynn HA. Preferences and perceived barriers to treatment for depression during the perinatal period. J Womens Health. 2008;17(8):1301-9.

13. Pinto-Foltz MD, Logsdon MC. Reducing stigma related to mental disorders: initiatives, interventions, and recommendations for nursing. Arch Psychiatr Nurs. 2009;23(1):32-40

14. DeRubeis R, Hollon S, Amsterdam J, Shelton R, Young P, Salomon R, et al. Cognitive therapy vs medications in the treatment of moderate to severe depression. Arch Gen Psychiatry. 2005;62:409-16.

15. Galbally M, Gentile S, Lewis AJ. Further findings linking SSRIs during pregnancy and persistent pulmonary hypertension of the newborn: clinical implications. CNS Drugs. 2012;26(10):813-22.

16. Ross LE, Grigoriadis S, Mamisashvili L, VonderPorten EH, Roerecke M, Rehm $J$, et al. Selected pregnancy and delivery outcomes after exposure to antidepressant medication: a systematic review and meta-analysis. JAMA Psychiatry. 2013;70(4):436.

17. Andersson G, Hesser H, Veilord A, Svedling L, Andersson F, Sleman O, et al. Randomised controlled non-inferiority trial with 3-year follow-up of internetdelivered versus face-to-face group cognitive behavioural therapy for depression. J Affect Disord. 2013;151(3):986-94.

18. Andrews G, Cuijpers P, Craske MG, McEvoy P, Titov N. Computer therapy for the anxiety and depressive disorders is effective, acceptable and practical health care: a meta-analysis. PLoS ONE. 2010;5(10):e13196.

19. Cavanagh K, Shapiro DA, Van Den Berg S, Swain S, Barkham M, Proudfoot J. The acceptability of computer-aided cognitive behavioural therapy: a pragmatic study. Cogn Behav Ther. 2009;38(4):235-46.

20. Gun SY, Titov N, Andrews G. Acceptability of Internet treatment of anxiety and depression. Australas Psychiatry. 2011;19(3):259-64.

21. Kaltenthaler E, Sutcliffe P, Parry G, Beverley C, Rees A, Ferriter M. The acceptability to patients of computerized cognitive behaviour therapy for depression: a systematic review. Psychol Med. 2008;38(11):1521.

22. Phillips R, Schneider J, Molosankwe I, Leese M, Foroushani PS, Grime P, et al. Randomized controlled trial of computerized cognitive behavioural therapy for depressive symptoms: effectiveness and costs of a workplace intervention. Psychol Med. 2014;44(04):741-52.

23. Proudfoot J. Clinical efficacy of computerised cognitive-behavioural therapy for anxiety and depression in primary care: randomised controlled trial. $\mathrm{Br}$ J Psychiatry. 2004;185(1):46-54.

24. Richards D, Richardson T. Computer-based psychological treatments for depression: a systematic review and meta-analysis. Clin Psychol Rev. 2012; 32(4):329-42.

25. Schneider J, Sarrami Foroushani P, Grime P, Thornicroft G. Acceptability of online self-help to people with depression: Users' views of MoodGYM versus informational websites. J Med Internet Res. 2014;16(3):e90.

26. Spek V, Cuijpers P, NyklíCek I, Riper H, Keyzer J, Pop V. Internet-based cognitive behaviour therapy for symptoms of depression and anxiety: a meta-analysis. Psychol Med. 2007;37(03):319.

27. Depression in adults: recognition and management. NICE [CG90]; 2009. http://www.nice.org.uk/guidance/cg90. Accessed 21 Dec 2015.

28. Antenatal and postnatal mental health: Clinical Management and Service Guidance. NICE [CG45]; 2007. http://www.nice.org.uk/guidance/cg192. Accessed 23 Feb 2016

29. O'Mahen H, Fedock G, Henshaw E, Himle JA, Forman J, Flynn HA. Modifying CBT for perinatal depression: what do women want? Cogn Behav Pract. 2012;19(2):359-71.

30. Stuart-Parrigon K, Stuart S. Perinatal depression: an update and overview. Curr Psychiatry Rep. 2014;16(9):468.

31. Lagan BM, Sinclair M, Kernohan WG. Internet use in pregnancy informs Women's decision making: a Web-based survey. Birth. 2010;37(2):106-15.

32. Gerhards SA, de Graaf LE, Jacobs LE, Severens JL, Huibers MJ, Arntz A, et al. Economic evaluation of online computerised cognitive-behavioural therapy without support for depression in primary care: randomised trial. $\mathrm{Br} \mathrm{J}$ Psychiatry. 2010;196(4):310-8

33. Kingston D, Janes-Kelley S, Tyrrell J, Clark L, Hamza D, Holmes P, et al. An integrated Web-based mental health intervention of assessment-referralcare to reduce stress, anxiety, and depression in hospitalized pregnant women with medically high-risk pregnancies: a feasibility study protocol of hospital-based implementation. JMIR Res Protoc. 2015;4(1):e9.

34. Stroup DF. Meta-analysis of observational studies in epidemiology: a proposal for reporting. JAMA. 2000;283(15):2008.

35. Liberati A, Altman DG, Tetzlaff J, Mulrow C, Gotzsche PC, loannidis JPA, et al. The PRISMA statement for reporting systematic reviews and meta-analyses of studies that evaluate healthcare interventions: explanation and elaboration. BMJ. 2009:339:b2700.

36. Hantsoo L, Epperson CN, Thase ME, Kim DR. Antepartum depression: treatment with computer-assisted cognitive-behavioural therapy. Am J Psychiatry. 2013;170(8):929-30.

37. Kim DR, Hantsoo L, Thase ME, Sammel M, Epperson CN. Computer-assisted cognitive behavioural therapy for pregnant women with major depressive disorder. J Womens Health. 2014;23(10):842-8.

38. Kersting A, Kroker K, Schlicht S, Wagner B. Internet-based treatment after pregnancy loss: concept and case study. J Psychosom Obstet Gynecol. 2011; 32(2):72-8.

39. Kersting A, Kroker K, Schlicht S, Baust K, Wagner B. Efficacy of cognitive behavioural internet-based therapy in parents after the loss of a child during pregnancy: pilot data from a randomized controlled trial. Arch Womens Ment Health. 2011:14(6):465-77.

40. Kersting A, Dölemeyer R, Steinig J, Walter F, Kroker K, Baust K, et al. Brief internet-based intervention reduces posttraumatic stress and prolonged grief in parents after the loss of a child during pregnancy: a randomized controlled trial. Psychother Psychosom. 2013;82(6):372-81.

41. Cochrane Consumers and Communication Review Group. Data Extraction Template for Cochrane Reviews. The Cochrane Collaboration; 2013. http:// cccrg.cochrane.org/author-resources. Accessed 23 Feb 2016

42. Verhagan AP, de Vet HCW, de Bie RA, Kessels AGH, Boers M, Bouter LM, et al. The Delphi list: a criteria list for quality assessment of randomized clinical trials for conducting systematic reviews developed by Delphi consensus. J Clin Epidemiol. 1998:51(12):235-1241.

43. O'Mahen HA, Woodford J, McGinley J, Warren FC, Richards DA, Lynch TR, et al. Internet-based behavioural activation-Treatment for postnatal depression (Netmums): A randomized controlled trial. J Affect Disord. 2013; 150(3):814-22

44. O'Mahen HA, Richards DA, Woodford J, Wilkinson E, McGinley J, Taylor RS, et al. Netmums: a phase II randomized controlled trial of a guided Interne behavioural activation treatment for postpartum depression. Psychol Med. 2014;44(08):1675-89.

45. Danaher BG, Milgrom J, Seeley JR, Stuart S, Schembri C, Tyler MS, et al. MomMoodBooster Web-Based Intervention for Postpartum Depression: Feasibility Trial Results. J Med Internet Res. 2013;15(11):e242.

46. Jacobson NS, Truax P. Clinical significance: a statistical approach to defining meaningful change in psychotherapy research. J Consult Clin Psych. 1991;59:12-9.

47. Matthey S. Calculating clinically significant change in postnatal depression studies using the Edinburgh Postnatal Depression Scale: a brief report. J Affect Disord. 2005;78:269-72.

48. Christensen $\mathrm{H}$, Griffiths KM, Farrer L. Adherence in internet interventions for anxiety and depression. J Med Internet Res. 2009;11(2):e13.

49. Kelders SM, Kok RN, Ossebaard HC, Van Gemert-Pijnen JE. Persuasive system design does matter: a systematic review of adherence to Web-based interventions. J Med Internet Res. 2012;14(6):e152.

50. Waller R, Gilbody S. Barriers to the uptake of computerized cognitive behavioural therapy: a systematic review of the quantitative and qualitative evidence. Psychol Med. 2009;39(05):705

51. Haga SM, Drozd F, Brendryen H, Slinning K. Mamma mia: a feasibility study of a Web-based intervention to reduce the risk of postpartum depression and enhance subjective well-being. JMIR Res Protoc. 2013;2(2):1-18.

52. Heller HM, van Straten A, de Groot CJ, Honig A. The (cost) effectiveness of an online intervention for pregnant women with affective symptoms: protocol of a randomised controlled trial. BMC Pregnancy Childbirth. 2014;14(1):273.

53. Kingston D, Austin M-P, Hegadoren K, McDonald S, Lasiuk G, McDonald S, et al. Study protocol for a randomized, controlled, superiority trial comparing the clinical and cost- effectiveness of integrated online mental health assessment-referral-care in pregnancy to usual prenatal care on prenatal and postnatal mental health and infant health and development: the Integrated Maternal Psychosocial Assessment to Care Trial (IMPACT). Trials. 2014;15(1):72. 